\title{
Exploring the Meaning of Shanghai Cheongsam from the Perspective of the Male Gaze
}

\author{
Yunlin Huang ${ }^{1, a, \dagger, *}$, Yuqing $\operatorname{Liu}^{2, b, \dagger, *}$, Fangxin Yang $3, c, \uparrow, * *$ \\ ${ }^{1}$ Department of Bi-lingual (Chinese and English) Secretary, School of Chinese Language and Literature, South China \\ Normal University, Guangzhou, Guangdong 510006, China \\ ${ }^{2}$ Business Administration College, Hebei University of Economics and Business, Hebei, Shijiazhuang 050000, China \\ ${ }^{3}$ Department of Film Studies, Film Studies (Film Criticism), Beijing Film Academy, Beijing 100088, China \\ *Corresponding author.Email: ${ }^{2} 20173501022 @ m . s c n u . e d u . c n,{ }^{b} 20141358 @$ stu.nun.edu.cn, ${ }^{c} 1020474435 @ q q . c o m$,
}

These authors contributed equally.

\begin{abstract}
The male gaze is a popular research angle in the media and fashion industry. Still, the current academic research on the phenomenon of the male gaze in China mainly started with literary works and consumer psychology, and the research angle was relatively scattered. From the perspective of the male gaze, this paper combs the changes of the meanings of Shanghai cheongsam in different historical stages. We hope that the paper can further enrich the background information of the male gaze and provide new ideas for the research of other scholars. The sources of data included an academic website, social media platforms, and an online survey. Through questionnaires, we studied the opinions of contemporary Chinese people towards Shanghai cheongsam in different contexts, and found out the mainstream and dominant meanings generated by this garment currently were "dignified" and "graceful", which tended to be positive, partly progressive, and heavily influenced by the government. When we further cross-contrasted the attitudes towards three typical types of the "Spouses of Warlords" video screenshots with the respondents' binary gender, finding that male respondents generally felt more positive than female respondents. From the perspective of viewing, with the combination of consumerism and patriarchy, Male Gaze was hidden behind the screen, reinforced the woman' s self-objectification unconsciously. Shanghai cheongsam, as a fashion, has become a political discourse in the complicated contemporary context. We expect that the phenomenon of the male gaze in Chinese society can be emphasized and concerned by more people politically and socially to advocate gender equality in the future society.
\end{abstract}

Keywords: Shanghai cheongsam, "Spouses of Warlords" Trend, Male Gaze, the Development of Meanings

\section{INTRODUCTION}

\subsection{The History of Cheongsam}

Cheongsam is one of the most representatives of traditional Chinese clothing, and its strong cultural colour and pluralistic cultural connotation make cheongsam synonymous with "Eastern female beauty". Cheongsam was originally a daily dress chosen by Manchu people for convenience, comfort, protection from the cold, and other life needs. The use of cheongsam gradually changed from the interior of the imperial palace to being recognized by the people in the Qing Dynasty. During its integration into Chinese society, the Manchu cheongsam adopted parts of Chinese fashion, including auspicious colors such as red or gold and symbols such as the dragon.

After the May Fourth Movement (1919), cheongsam was back in style due to female Han students in Shanghai, who imitated males by dressing to reveal their ambition to achieve aspirations politically and socially as men did. During this period, cheongsam was relatively similar to the traditional Manchu style, being loose and wide, with a high neck and narrow sleeves. Then, affected by the styles of Europe and America, the cutting of cheongsam became much bolder. Some side silts almost slashed to the hips. While exposing more skin, it was also more close-fitting to outline the curves of the eastern female body.

Wang Di, a Chinese scholar, once summed up the cultural connotation of cheongsam: "cheongsam is a 
female dress with traditional charm and modern vitality. Its past is unpredictable, and its present is keeping pace with the times"[1]. This coincides with Joanne Entwistle's view that fashion is a specific dressing system that appears in a specific social environment, illustrating the delicate relationship between clothing, fashion, and social change [2].

\subsection{Literature Review}

Previously, scholars in different fields have conducted in-depth research on cheongsam from the perspectives of clothing design, historical context, ethics, aesthetic changes, and so on. However, the image of Chinese women shaped by cheongsam has rarely been examined directly in all kinds of articles. Susan B Kaiser, a famous American clothing psychologist, concluded that "Fashion shapes Women". She believes that style-fashion-dress completes the shaping of women themselves through visualization. In the visualization process, all kinds of female elements are added to the clothing design, which solidifies the standard of the female image in people's minds [3]. The early cheongsam wrapped the beautiful curve of women in straight and fat cloth, restraining women's daily actions and forbidding their spiritual freedom. In the later period, although the cheongsam was improved by drawing lessons from the western aesthetic, it still failed to break through the shackles of traditional thought on women. The combination of Western-style cutting and Chinese-style buckle and skirt design also contradicts the deep meaning of cheongsam itself [4].

\section{3. "Spouses of Warlords" Trend on Tiktok}

When sorting out the materials of the cultural connotation of modern cheongsam, the film "Spouses of Warlords" on the short video platform and its social and cultural impact in the local society was worth noting. During the past 3 years, "Spouses of Warlords" has become a hot video creation subject on social networking services such as Tiktok-"Spouses of Warlords" trend. This upsurge caused controversy among netizens, and the major media also reported and commented on this phenomenon one after another. As cheongsam was one of the core elements in this trend, we focused on this phenomenon. Moreover, it would be of special interest to further explore the effect of the male gaze on the connotation of cheongsam under the perspective of gender differences. Our paper aims to review the typical cheongsam in different historical periods and explore the influence of cheongsam on the image shaping of Chinese women. At the same time, the article will take the male gaze perspective to analyse the "Spouses of Warlords" trend to generate a deeper understanding of the influence of gender factors on the dissemination of the meaning of contemporary cheongsam.

\subsection{Organization of this article}

The second part of this article introduces the research methods and data source. In the third part of the article, we will sort out Chinese women's images under the cheongsam culture. This part will involve the relevant concepts of folklore, sociology, ethics, and other disciplines. Moreover, the phenomenon of "Spouses of Warlords" on TikTok (Chinese version) will be explored based on our survey data. We will use the relevant theory of the male gaze to analyse the gender-influenced differences in the questionnaire in detail. In the final part, we will speculate on the influence range of the male gaze on the meaning of cheongsam and also predict the trend of the meaning of cheongsam in the future.

\section{METHOD}

The framework for the research strategies included survey and data analysis. To be specific, we conducted a survey involving questionnaires of the opinions of contemporary Chinese people towards cheongsam in different contexts, and a statistical website WJX was used to analyze the primary data from the survey.

Regarding the survey, as shown in Table 1, the questionnaire consisted of 21 questions in total, among which the first 20 are compulsory close-ended questions, and the last one was an optional open-ended one for respondents with further views. As a less common type of question, the graphic section below intended to assist participants in figuring out what messages they received by comparing and contrasting 7 images that conveyed various meanings of cheongsam in several contexts.

We mainly targeted the Chinese general public who volunteered to participate in the survey on three Chinese mainstream social networking services, WeChat, QQ, and Weibo, between Mar 15th and Mar 19th, 2021. As a requisite, all the participants understood how their answers were used and their personal information was protected. By means of WJX, an online crowd-sourcing platform, the survey used a random sample of 160 Chinese in all age brackets. Since 2 questionnaires completed within 50 seconds were deemed as invalid, a total of 158 participants constituted our final sample with a validity rate of $98.75 \%$. Specifically, female respondents were slightly more than males, at approximately $54.43 \%$, while the latter portion was $45.57 \%$. Most of the participants $(40.51 \%)$ were $19-25$ years old, $74.69 \%$ of them were from cities, especially metropolises (43.04\%), and over half of them (57.59\%) had bachelor's degrees. 
Table 1. Structure of the questionnaire except for the last optional open-ended question

\begin{tabular}{ll}
\hline Basic Information & Gender \\
4 questions & Age \\
& $\begin{array}{l}\text { Educational Background } \\
\text { Current Location }\end{array}$ \\
\hline General Impression of Shanghai & Preference on Shanghai Cheongsam (Likert scale) \\
Cheongsam & Acceptance of Shanghai Cheongsam wearers (Likert scale) \\
3 questions & Main Communication channels of Shanghai Cheongsam Culture \\
& (Multiple choice) \\
Different Meanings of Shanghai & Shanghai Cheongsam Worn by Qingling Song in the 20th Century \\
Cheongsam Generated by & Shanghai Cheongsam Worn by Actress in 2000 \\
Pictures & Shanghai Cheongsam Worn by Female Students in the 20th Century \\
7 questions; Multiple choice & Shanghai Cheongsam Worn by Influencers on Tiktok in "Spouses of \\
& Warlords" Trend
\end{tabular}

General Opinions towards

Shanghai Cheongsam presented in the " Spouses of Warlords"

Familiarity of History of the Warlords' Spouses (Likert scale)

Trend

4 questions

\section{RESULTS AND DISCUSSION}

In this section, we first delved into the development of meanings generated by Shanghai cheongsam shown in our survey from the perspective of contemporary Chinese. We analyzed gender differences on certain graphic questions in the questionnaire to illustrate how meanings conveyed by cheongsam were diverse between two genders.

\subsection{The Development of Meanings Generated by Shanghai Cheongsam}

The existing meanings conveyed by Shanghai cheongsam were mainly divided into the nongovernmental context and the official one, for the meanings from the former tend to be more complicated and variable, while that from the latter seem to constantly embody one explicit and positive meaning since 20 century.

\subsubsection{Nongovernmental Context}

In this context, cheongsam meanings were controversial, with positive and negative, progressive and conventional factors.

\subsubsection{In the 1920s: Rebellious and Heroic}

Cheongsam originally embodied rebellion and a gesture of heroic [6]. As shown in figure 1, it has been redefined as a uniform and after-school outfit by progressive feminists since the May Fourth Movement in 1919. Thus it has been a call for feminism thanks to its unisex characteristic and origin as males' robe [7]

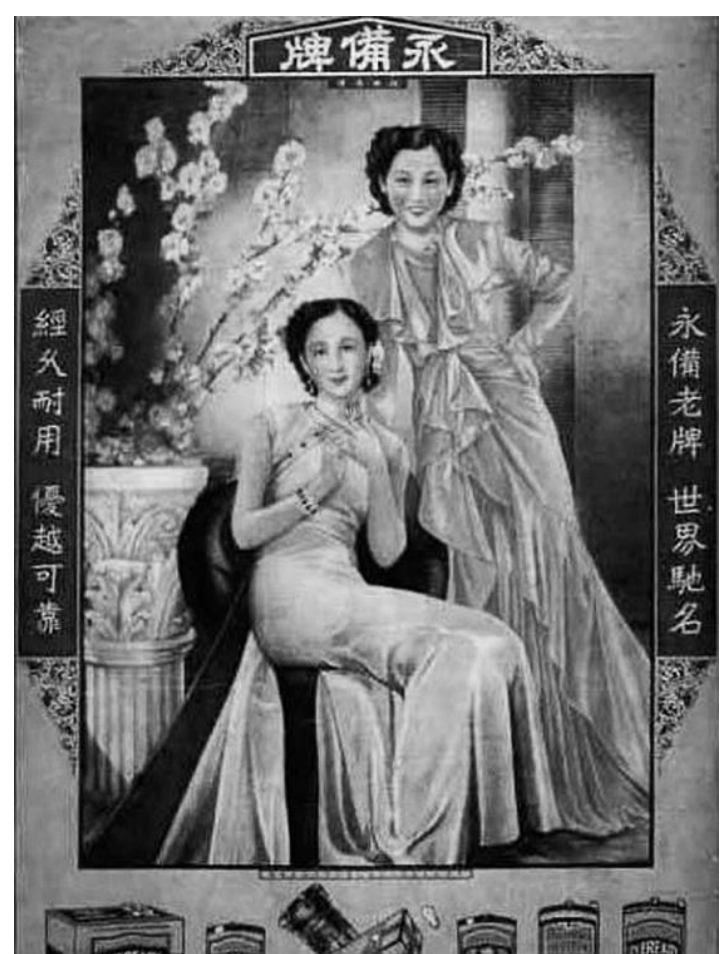

Figure 1 Shanghai Female students in 20 century [5] 


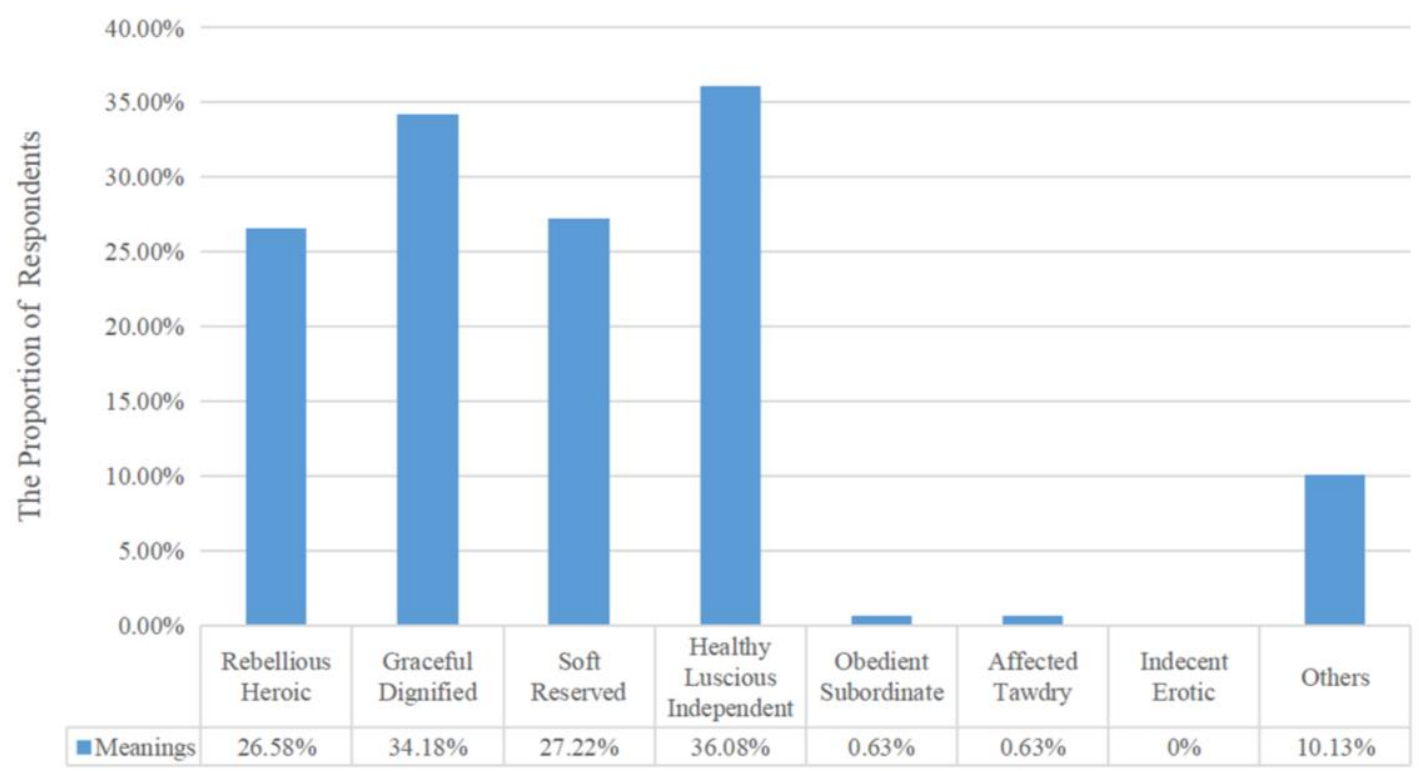

Figure 2 Respondents' attitude towards the Shanghai female students in Shanghai cheongsam in 20 century

However, according to the survey, the biggest proportion of respondents considered this kind of cheongsam as healthy, luscious, and independent (36.08\%), followed by $34.18 \%$ of them appreciating its dignity and grace. Only $26.58 \%$ of respondents received its rebellious and heroic message, slightly less than those associating with softness and reservedness $(27.22 \%)$.

Consequently, though most of the implications were positive, contemporary Chinese seemed to fail to identify the rebellious and feminist idea in cheongsam, which may be related to their unfamiliarity with cheongsam historical background.

\subsubsection{From the 1930s to 1940s: Modern and Conventional}

In terms of people today, significantly, over half of the respondents shared a sense of dignity and grace $(54.43 \%)$ from this image, with $37.34 \%$ and $29.11 \%$ of them associated this kind of cheongsam with softness, reservedness, and modernity, independence, respectively.

Conversely, there were also some negative implications showing up. Though their portions were relatively smaller, it was worth noticing that this image received the most passive feedback comparing to other 20 century graphics. Specifically, some respondents deemed it an obedient and subordinate gesture (7.59\%), while others even found it affected and tawdry $(8.23 \%)$.

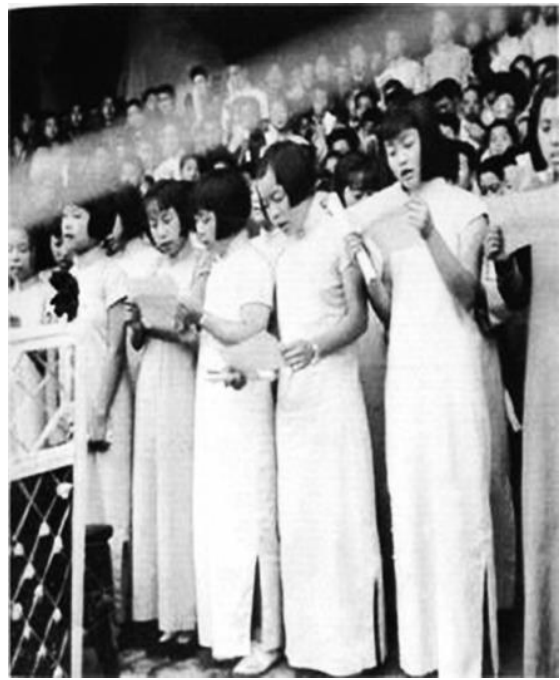

Figure 3 Two females in Shanghai cheongsam on an advertising poster from a calendar in the late 1930s [8]

The general public's attitude towards cheongsam on this commercial poster could be complicated based on the data.

On the one hand, Shanghai cheongsam conveyed progressive messages as the emancipation of female bodies, especially during its Bronze Age from the 1930s to 1940s [9]. It symbolized the idea of "modernity": pursuing health, fashion, and natural beauty [10]. Influenced by western progressive feminism, the shift of cheongsam turning from initially loose and androgynous to tight and feminine was preferred by trendy Shanghai women who were glad to reveal their natural curved shape. This prevalence mirrored the changes in women's identities and their concepts of the ideal womanhood against the Confucian ideology: instead of being petite and fragile, females should be healthy, luscious, and independent. 
On the other hand, patriarchy and commerce, to some extent, subverted cheongsam feminism ideas into conventional values and associated them with males' fantasies. As shown in figure 4, using graphics of attractive women as the major image, calendar posters played an essential role in the prevalence of Shanghai cheongsam since exhibiting female seductive and shapely bodies did serve as an effective promotion [11].

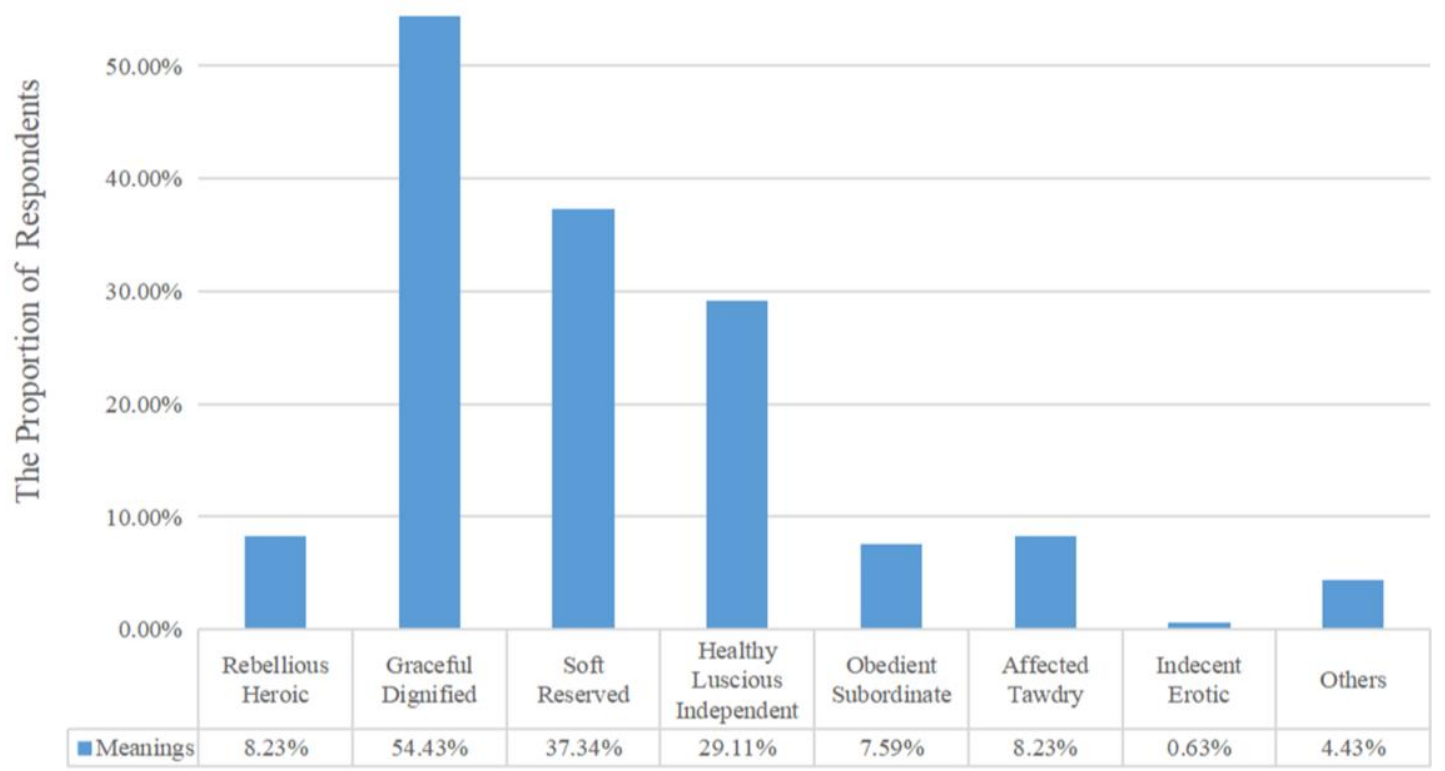

Figure 4 Respondents' attitude towards two females in Shanghai cheongsam on the poster from a calendar in the late 1930 s

Under this circumstance, it was also common that some females in Shanghai cheongsam revealed their bodies to satisfy the male's fantasies of female attractiveness to meet their commercial demands. Because they provided pleasant association for males involving prostitutes sing-song girls or high-class-call girls. For instance, some presented an obedient and subordinate image fulfilling males" "qualified wife" imagination by displaying their feminine attributes as a mark of their gender based on the Confucian ideology. In contrast, others, conversely, might be deemed as affected, tawdry, indecent, and even erotic [12].

As a result, Shanghai cheongsam may indicate positive and progressive ideas. Also, it could be taken as a negative and conventional return to traditional women's role and status in both family and society.

\subsubsection{3 in the Early 21st Century: Soft and Reserved}

Shanghai cheongsam was commonly seen in 21 century Chinese movies. Renowned for its gorgeous cheongsam costumes and promising aesthetic value, In the Mood for Love, a romance movie directed by Wong Karwai, conveyed the subtleties of restraining affection and desire.

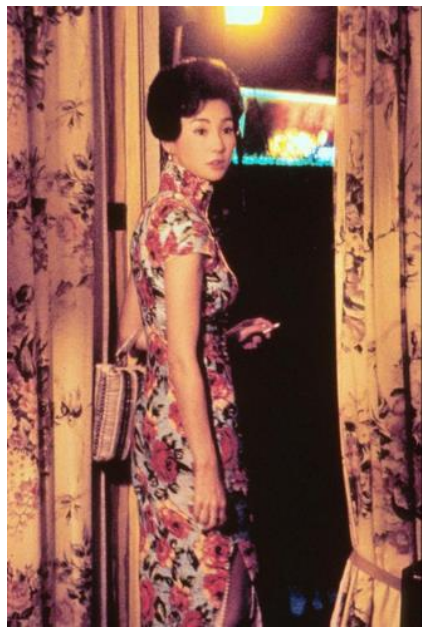

Figure 5 A character in Shanghai cheongsam on a still from the movie, In the Mood for Love, 2000 [13]

As for this still, the majority of respondents held the opinion of dignity and grace $(39.24 \%)$. A sense of softness and reservedness and health, lusciousness, and independence were also noticeable, accounting for $36.08 \%$ and $31.65 \%$ separately. Whereas $12.66 \%$ of them received obedient messages and symbolized it as a subordinate to men. Additionally, very few people considered it as affected and tawdry (3.16\%). 


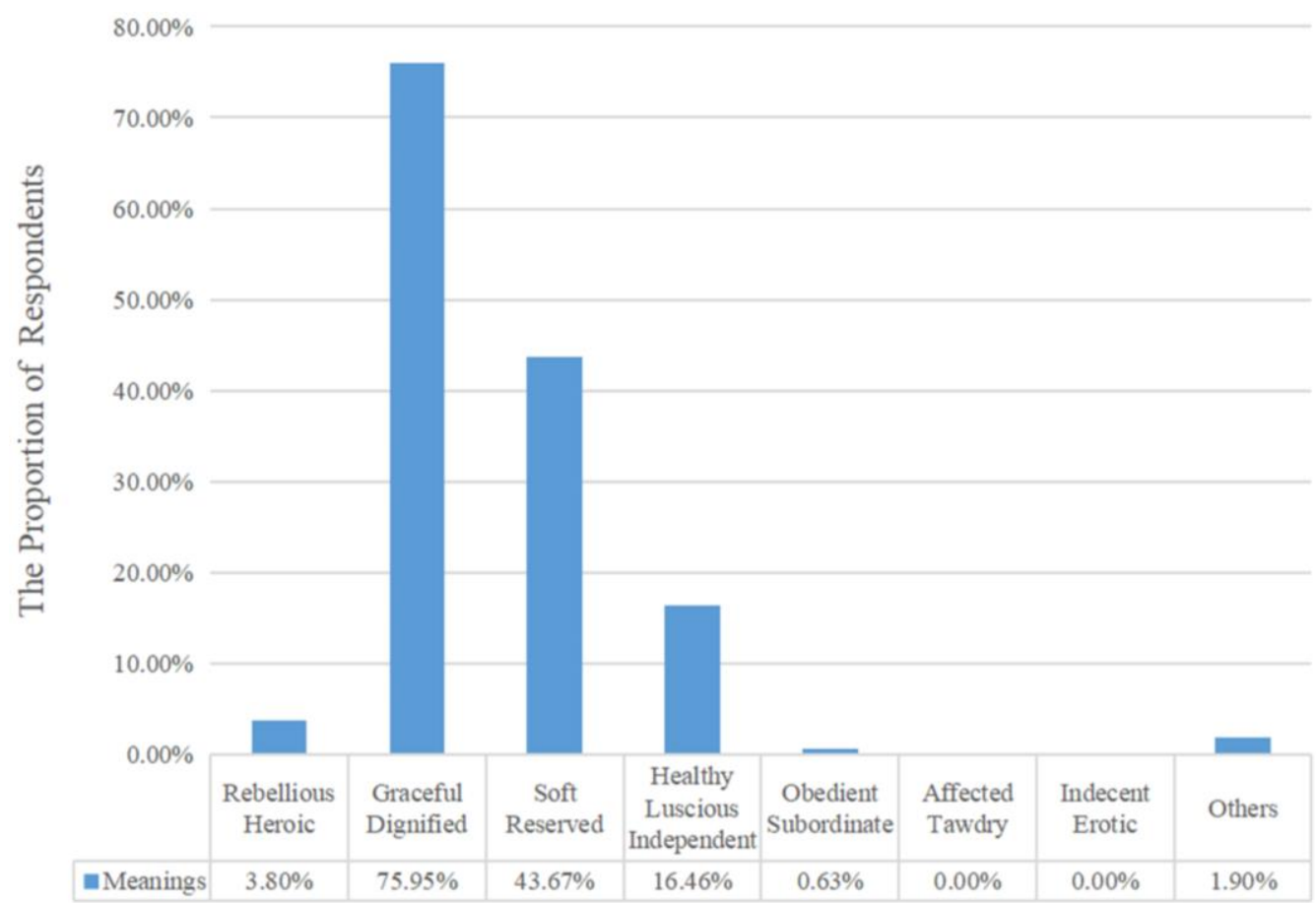

Figure 6 Respondents' attitude towards the character in Shanghai cheongsam on a still from the movie, In the Mood for Love, 2000

Apparently, respondents' attitude was diverse. For those who appreciated this image, Maggie Zhang, the heroine, presented the distinctive glamour of ideal contemporary Chinese women, being elegant and soft and implicitly sensual [14]. In comparison, those negative comments were probably relevant to this certain movie character and the cinematography, which was beyond the scope of this study.

\subsubsection{Governmental Context}

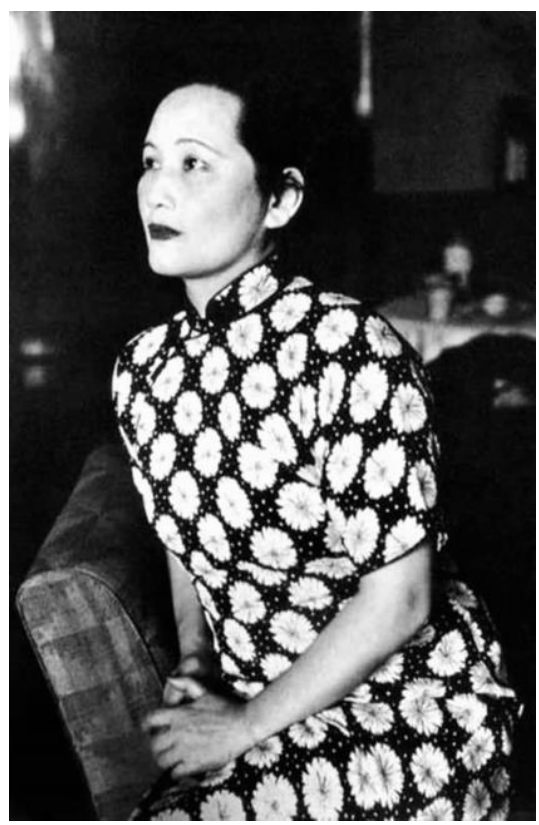

Figure 7 Qingling Song in flowery Shanghai cheongsam in 20th century [15]
Unlike the complicated and diverse meanings conveyed by cheongsam wearers among the common people, Shanghai cheongsam, on the contrary, has generated much more simple and explicit meanings officially, representing grace and dignity since the 20th century.

In general, almost all the respondents received positive meanings from this image. Noticeably, a sense of dignity and grace was shared by $75.95 \%$ of respondents, while $43.67 \%$ of them deemed this kind of cheongsam as soft and reserved. 


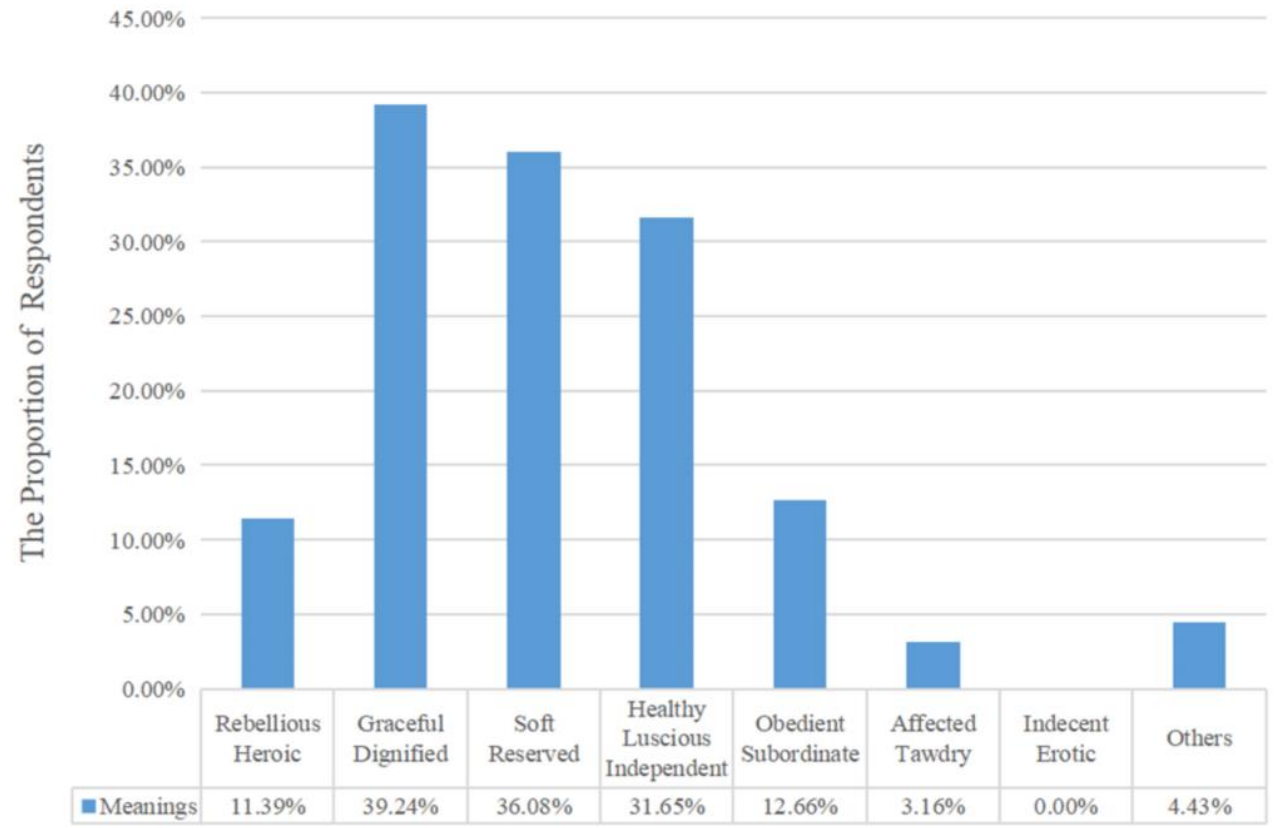

Figure 8 Respondents' attitude towards Qingling Song in flowery Shanghai cheongsam in 20th century

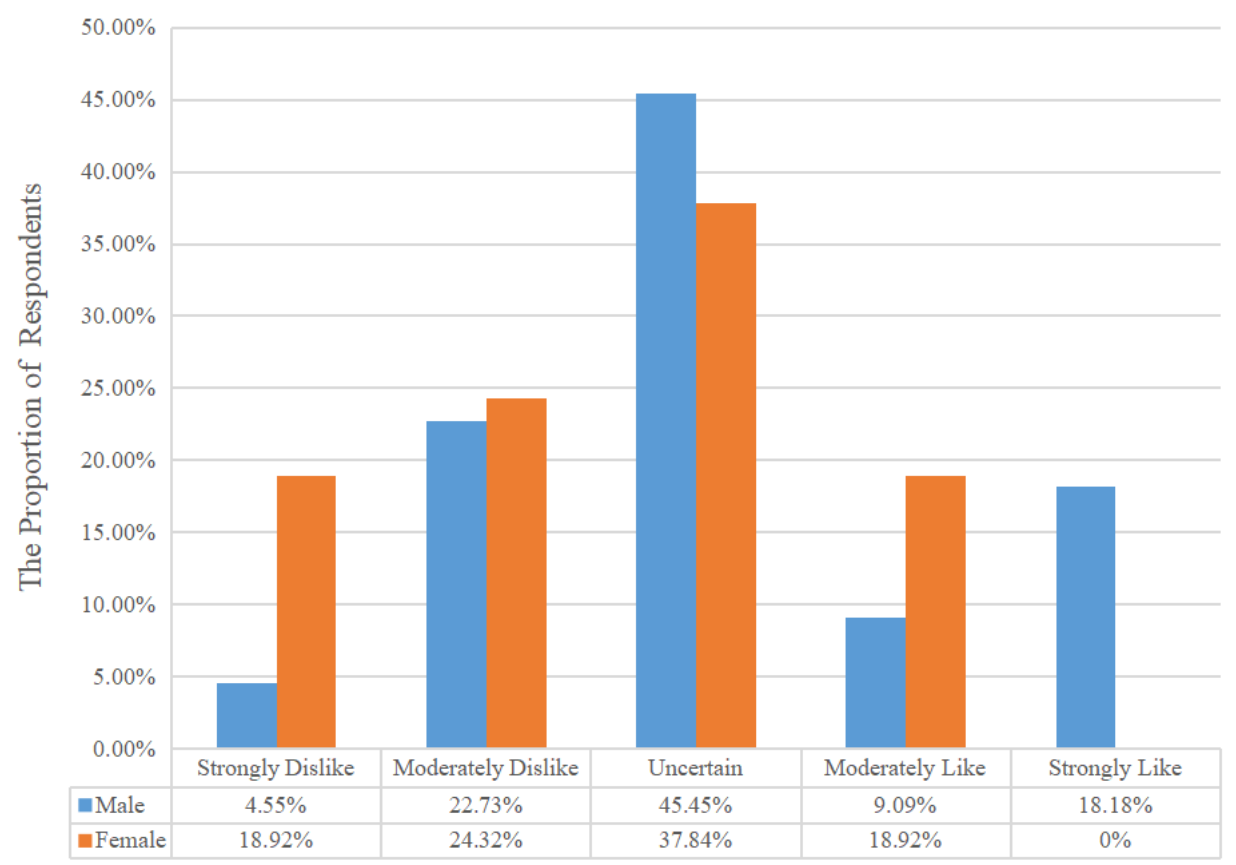

Figure 9 The preference of the "Spouses of Warlords" videos 


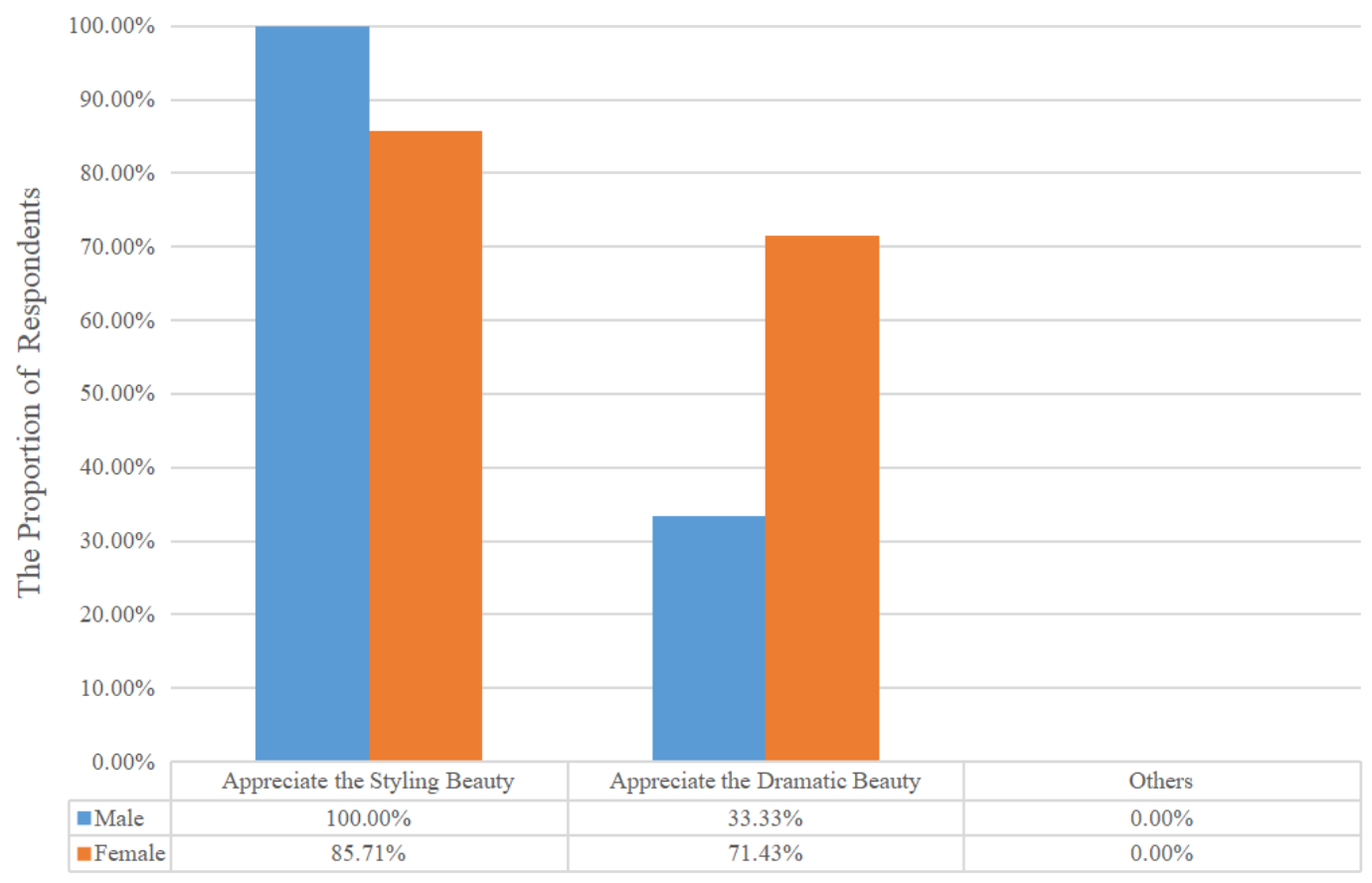

Figure 10 The reason why respondents like the "Spouses of Warlords" videos

Cheongsam's well-known history might explain that it was designated as a national suit by the Nanjing Government in 1929 and was then popularized by QinglingSong (1893-1981), spouse of Sun Yetsan. Song remained a revered and uncontested figure [16]. Due to her high prestige and political status, in many cases, people admired her. Naturally, they took her as the ideal image of a female leader whose dressing code for her leadership was understated elegance. Furthermore, these two popular choices also partly reflected the traditional value towards females' virtues, roles, and status domestically and socially.

To summarize, the mainstream meanings generated by Shanghai cheongsam were dignified and graceful, as it was mainly the dominant implication among the graphics above. It also indicated that the government played a relatively essential role in shaping the public's opinions towards the ideal image of cheongsam. Moreover, the shared senses of softness, reservedness, and health, lusciousness, independence were also widely accepted meanings of this garment.

Although certain conventional and negative elements exist, Shanghai cheongsam meanings generally tend to be positive and partly progressive for contemporary Chinese.

\subsection{Meanings Analysis In the context of "Spouses of Warlords" Trend}

After knowing the contemporary Chinese people' $\mathrm{s}$ feelings about the female image of cheongsam in the past, we might as well come to the present. In the context of the "Spouses of Warlords" trend during the last three years, what meanings has the Shanghai cheongsam conveyed, and what kind of female image has it shaped?

Since we are cutting in from the perspective of the audience's perception, we might as well pay attention to the field conversion of viewing. Tracing back to the specific historical time point of the development of Shanghai cheongsam mentioned above, people initially watched it with the naked eye. Then from painting posters to the big screen movie that needed to be looked up, until today, in the "Spouses of Warlords" trend, people just looked down and swiped their mobile screens. Benjamin' s theory in 1935 illustrated such evolution well: As the mechanical reproduction went deep into the life and the viewing distance was getting closer, Aura disappeared and was replaced by the political participation of the viewer [17]. In the context of the "Spouses of Warlords" trend, worship value disappeared completely and became a display value, which indicates the characteristics of a secular, capitalist commodity.

There is no image without the viewer in this visual culture, which is strongly related to the gender relations in viewing. In 1973, John Berger pointed out that women, as self-censors, actually examine them from a male perspective [18]. Then Laura Mulvey made a further case study on the viewing relationship and introduced the concept of Male Gaze in 1975, which has been widely used to analyze and examine various phenomena since then. Therefore, based on data from the questionnaire, we will use Male Gaze to examine the gender relationship of viewing in the context of the "Spouses of Warlords" trend and the effect on the female image of Shanghai cheongsam. 


\subsubsection{Indications of Male Gaze In the context of "Spouses of Warlords" Trend}

As shown in Figure 9, male respondents like to watch the "Spouses of Warlords" videos more than women generally. Based on calculations, the male' $\mathrm{s}$ Likert scale is 3.14 while the female's is 2.57 , which confirms the influence of the Male Gaze in the trend.

When it comes to why the respondents like the "Spouses of Warlords" videos, there is a gender difference which is worth concerning, as shown in Figure 10: Though both men and women appreciate the styling beauty (sexy, charming, elegant) more than the dramatic beauty, all the men appreciate the styling beauty and the women appreciate more than twice as much the dramatic beauty (surprising, hilarious) as men.

Surprisingly, all the men appreciate the styling beauty. Why? As Tara Well analyzed, "Female characters must perform their story function while also adhering to the heterosexual male sexual fantasy though not always in a literal way. Simply being beautiful (or "sexy") is all that' s needed" [19]. Also, the open and collective viewing assuredly strengthens the reasonableness of Male Gaze, promoting the consumption of the female body and multiple symbols underneath its figure.

\subsubsection{Gender Difference in Response of Three Types of the "Spouses of Warlords" Video Screenshots}
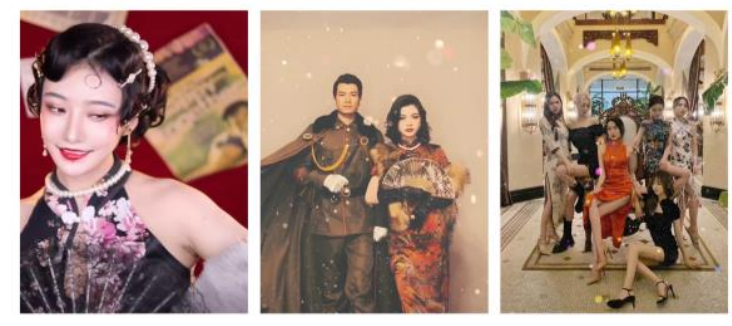

01 Makeup Transformation 02 Role Play

Figure 11 Three types of "Spouses of Warlords" videos

There were three typical types of videos in the "Spouses of Warlords" trend: Makeup Transformation, Role Play, and Makeup Looks. The performers in the Makeup Transformation videos first exit with a normal appearance and then dress up to highlight the drama. Role Play videos are inclined to imitate historical images, and Makeup Look videos are simply imaged displays.

As shown in Figure 11, we found a gender difference in perceptions of these 3 types of the "Spouses of Warlords" video screenshots.

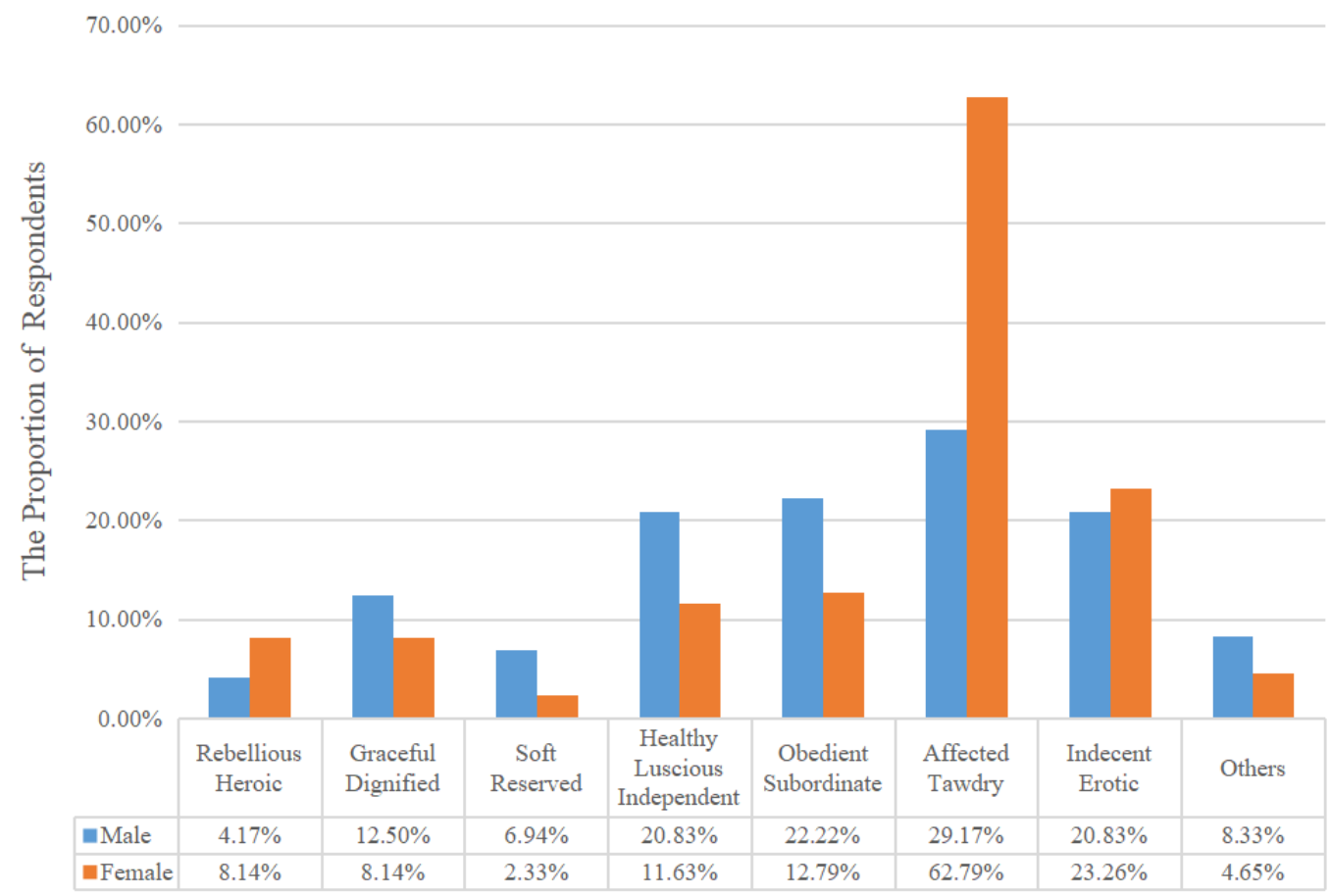

Figure 12 Respondents' attitude towards "Makeup Transformation" videos 


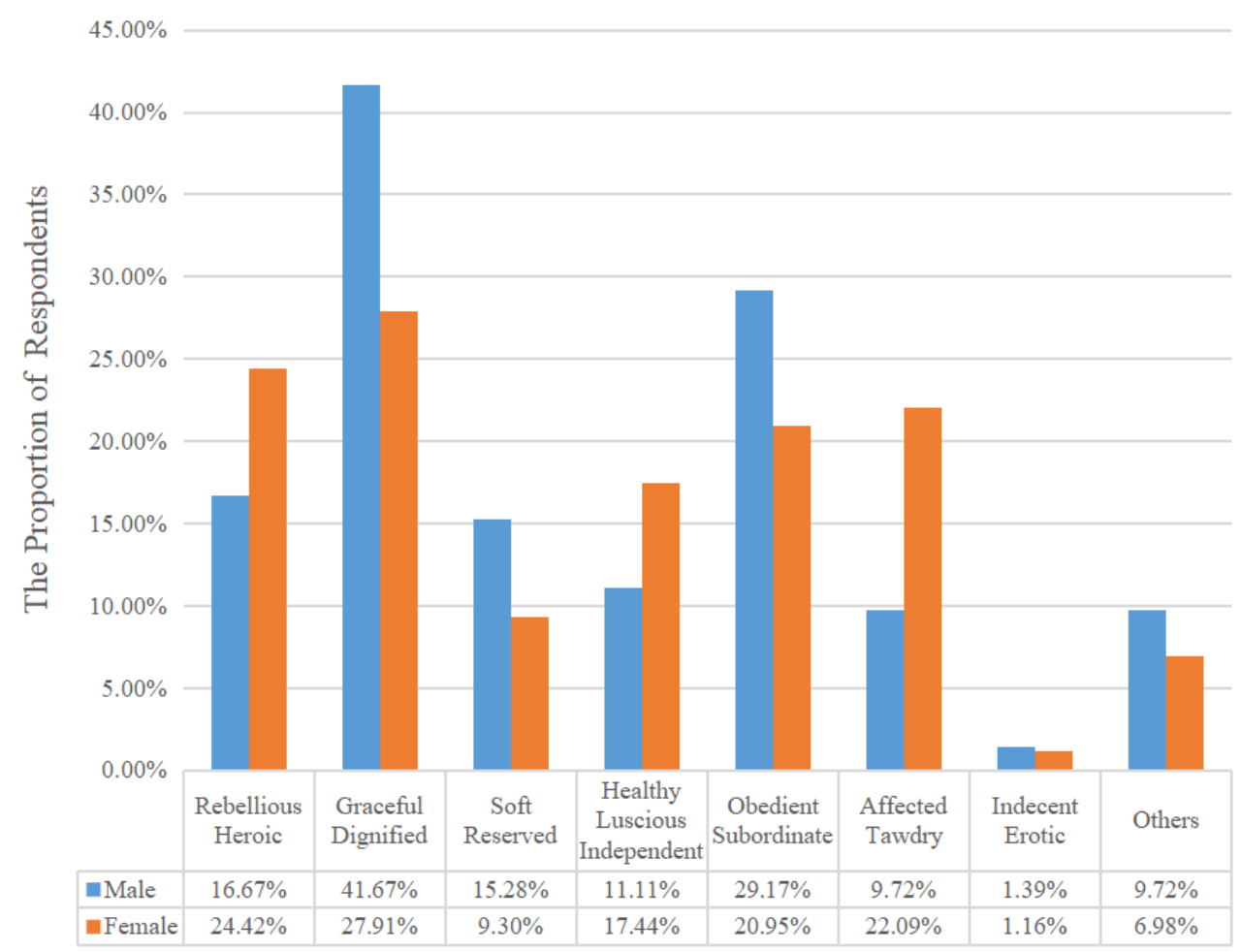

Figure 13 Respondents' attitude towards "Role Play" videos

For the Makeup Transformation screenshot, as shown in figure 12, the biggest proportion of female respondents considered the cheongsam image as Affected and Tawdry (62.79\%), while only $29.17 \%$ male respondents considered so. Women generally tend to view this screenshot negatively, while men tend to be neutral. Why are female viewers more critical of the appearance of female performers?

Male Gaze is essentially a process of projecting fantasy and encoding female images. However, the subject of implementation and consumption is not only men but also women. For those female viewers affected by Male Gaze, resulting in that they pay more attention to the appearance of the female performers. "They began to internalize this observer view of their bodies as a primary way to think about themselves and end up falling into the terrible logic of self-reification, placing greater value on how they look than how they feel" [20]. This process of habitual body monitoring, wherein women monitor their bodies as they believe outside observers do, is called self-objectification.

Opposed to Affected and Tawdry, the traditional image of a noble and elegant cheongsam woman is still an imaginary paradigm. Female respondents made image requests to the women in these screenshots to examine and criticize from the observer view, unconsciously promoting the power of Male Gaze and hiding the persecution of women by consumerism.

For the Role Play screenshot, as shown in figure 13, nearly half of male respondents $(41.67 \%)$ considered the cheongsam image as Graceful and Dignified, followed as Obedient and Subordinate (29.17\%). Female respondents chose more of the Graceful and Dignified (27.91\%), Rebellious and Heroic (24.42\%), Affected and Tawdry (22.09\%), Obedient and Subordinate $(20.95 \%)$. Men generally tend to view this screenshot positively, while women tend to be neutral.

Judging from the attitude of the male interviewees, this screenshot partly accords with the imagination of the female cheongsam image in the male gaze: Graceful and Dignified, which is exactly what women demand from performers in Figure 12.

In addition, both adjectives chosen by male respondents emphasized a sense of order. We need to pay attention to that this screenshot adds a male role, whose presence might greatly increase the authority and make the overall look with dignity. Also, based on the historical context of Role Play pursuits, dignity and obey are what the patriarchal society requires for traditional women. But on the other hand, this screenshot does not only display women. Putting men and women in the same position to be viewed subverts Male Gaze to a certain extent. 


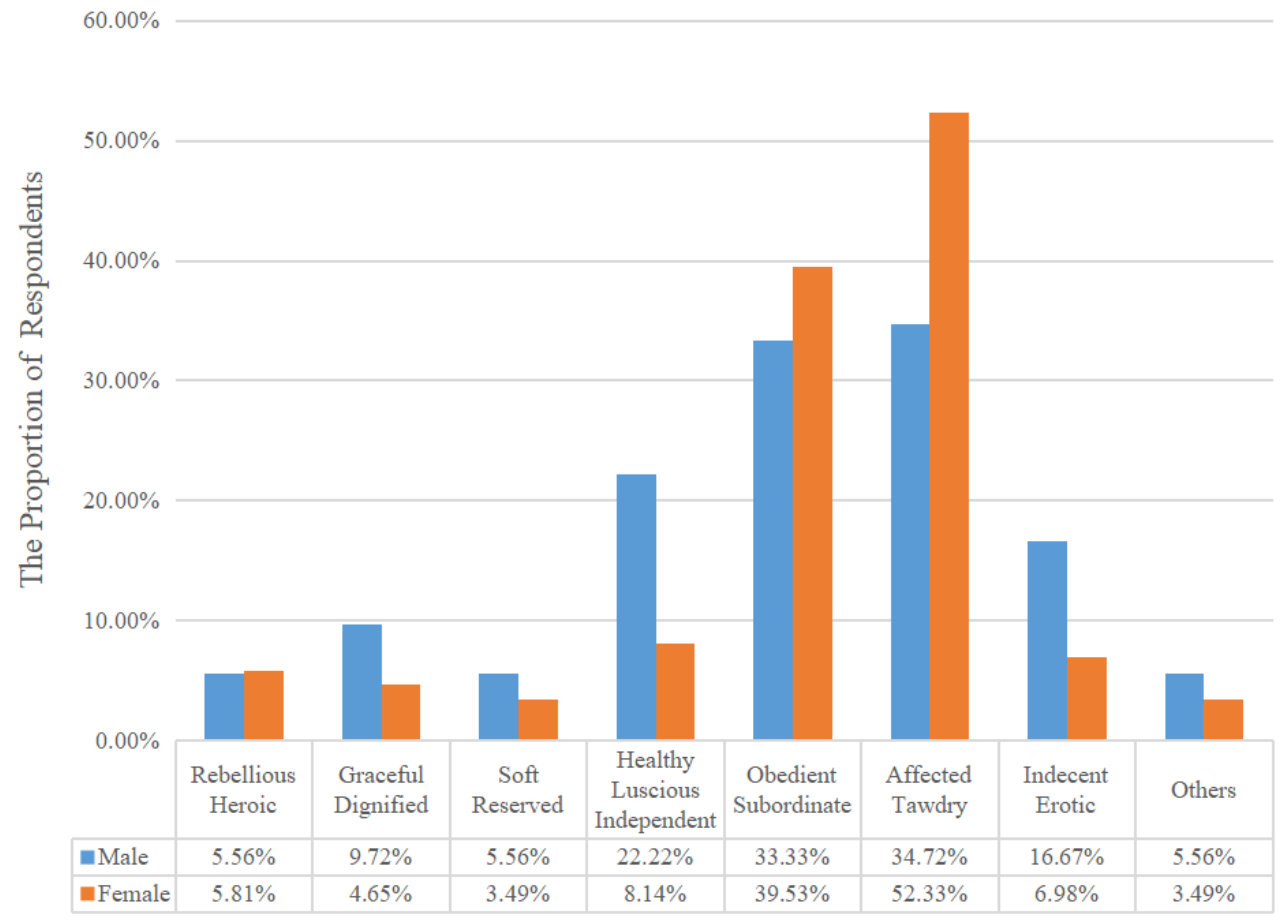

Figure 14 Respondents' attitude towards "Makeup Look" videos

The attitude towards the role play screenshot is similar to the makeup transformation, as shown in figure 14 , more than half of female respondents $(52.33 \%$ ) considered the cheongsam image as Affected and Tawdry, followed as Obedient and Subordinate (39.53 $\%)$. Among the male respondents, the biggest two proportions are also these two, respectively with 34.72 $\%$ and $33.33 \%$. In general, both men and women tend to view this screenshot negatively. This is probably because the gathering of "Spouses of Warlords" reveals the bad traditional logic of comparison and competition among women, which is one of the most obvious representations in which women are objectified.

In summary, from the perspective of viewing, Male Gaze existed in the "Spouses of Warlords" trend and reinforced the woman' s self-objectification, which made the meanings conveyed by Shanghai cheongsam tend to be conventional and negative.

\section{CONCLUSION}

Clothing is a special cultural symbol reflecting the fashion and flavor of an era. Influenced by several political and social reforms, the development of cheongsam has involved conflicts and fusions between traditional and modern value ideas, thus producing new significance. This paper discussed the changes in the meanings generated by Shanghai cheongsam in different stages from the perspectives of the male gaze.

Even though the meanings of Shanghai cheongsam might be complicated and variable, according to the survey, "dignified and graceful" was proved to be the mainstream and dominant opinion towards this garment in both governmental and nongovernmental context, with remarkably positive implications. As we predicted, this idea is of great likelihood to be the most widely accepted one continuously, as it has been since the 20th century.

In the context of the "Spouses of Warlords" trend in the 21 st century, although the respondents had different feelings about three typical types of video screenshots, the meaning of Shanghai cheongsam was conventional and negative in general. From the perspective of viewing, with the combination of consumerism and patriarchy, Male Gaze was hidden behind the screen, reinforced the woman's self-objectification unconsciously. Shanghai cheongsam, as a fashion, has become a political discourse in the complicated contemporary context.

In today's society, with the increasing economic status of women and the gradual enhancement of female subject consciousness, more and more women attempt to subvert the patriarchal structure. For instance, some has changed their dressing code from satisfying males to expressing themselves, while some are still trapped by feudal and conventional value and mindset, suffering from all kinds of prejudices, discrimination, and stereotypes. We expect that, by exploring how meanings generated by Shanghai cheongsam were diverse, the phenomenon of the male gaze in Chinese society can be emphasized and concerned by more people politically and socially to advocate gender equality in the future society. 


\section{REFERENCES}

[1] D. Wang, The Historical Changes in Chinese Qipao, Anhui Science Education Research Association, 2014, p. 73.

[2] J. Entwistle, The Fashion Body: Fashion, Dress, and Modern Social Theory, Polity, 2000.

[3] S.B. Kaiser, Fashion and Cultural Studies, A\&C Black, 2012.

[4] Y. Tang, On the rise and fall of cheongsam from the perspective of female consciousness, Journal of South China Normal University, 2007, pp. 86-88.

[5] D.D. Zhang. (2012). The research and design of Republic cheongsam decorating techniques. (Ma thesis, Beijing Institute of Fashion Technology).https://kns.cnki.net/KCMS/detail/deta il.aspx d dbname $=$ CMFD201301 $\&$ filename $=101312$ 5239.nh.

[6] X.F. Zhang, X.M. Yang, The Historical and Cultural Differences of Relationship between People and Garments- the Research on Female Clothing Trend in the late Qing Dynasty and the Republic of China, Guangdong Social Science(02), 2021, pp. 138-146.

[7] S. Ng, Gendered by Design: Qipao and Society, 1911 - 1949, Costume, 49(1), (2015) 55-74.

[8] E.J. Laing, Visual evidence for the evolution of" politically correct" dress for women in early twentieth century Shanghai. Nan nü, 5(1) (2003) 69-114.

[9] M.X. Bao, Shanghai Cheongsam in the First Half of the 20th Century. Decoration (05) (2000) 11-12. DOI: 10.16272/j.cnki.cn11-1392/j.2000.05.005.

[10] F. Yao, The research on the body shaping on Chinese women (1870-1950) - focusing on the modernization of bodies, Gansu Social Science (03) (2012) 111-115. DOI: 10.15891/j.cnki.cn62-1093/c.2012.03.022.

[11] E.J. Laing, Visual evidence for the evolution of" politically correct" dress for women in early twentieth century Shanghai. Nan nü, 5(1) (2003) 69-114.

[12] A. Finnane, What should Chinese women wear?: A national problem. Modern China, 22(2) (1996) 99-131.

[13] N.J. Tu. (2019). The research on cheongsam of the Republic of China based on the perspective of the awakening of Feminine Consciousness. (Ma thesis, Hunan Technology University).
https://kns.cnki.net/KCMS/detail/detail.aspx?dbna me $=$ CMFD202001\&filename $=1020609842$. nh.

[14] X.X. Tang.(2005).The interpretation of aesthetic implication of cheongsam.(Ma thesis, WuhanUniversity).https://kns.cnki.net/KCMS/detai 1/detail.aspx?dbname $=$ CMFD0506\&filename $=2006$ 034444.nh.

[15] J.J. Xu. (2019). A Practical Report on Clothing Translation in Funny Stories in Min Guo from the Perspective of Functional Equivalence (Ma thesis, Xinyang Normal University).https://kns.cnki.net/KCMS/detail/detail .aspx?dbname $=$ CMFD201902 $\&$ filename $=1019122$ 161.nh

[16] V. Wilson, Dressing for leadership in China: Wives and husbands in an age of revolutions (1911 1976). Gender \& history, 14(3) (2002) 608-628.

[17] W. Benjamin, The Work of Art in the Age of Mechanical Reproduction. Penguin Books Ltd, 2008.

[18] J. Berger, Ways of Seeing. Penguin Books Ltd, 2008

[19] K. Leonard, What is the Male Gaze? Definition and Examples in Film. [Online]Retrieved February 12, 2020, from https://www.studiobinder.com/blog/what-is-the-ma le-gaze-definition/

[20] T. Well, Taking Back the Male Gaze. Psychology Today. [Online]Retrieved November 06, 2017, from https://www.psychologytoday.com/us/blog/the-clar ity/201711/taking-back-the-male-gaze 